\title{
Theory of Chaos and Turbulence in Regional Economic Modelling
}

\author{
Peter NiJKAMP
}

\begin{abstract}
The paper focusses attention on recent disappointments concerning the limited predictive value of economic modeling. Major events -both international and national-could hardly be foreseen on the basis of our current analytical apparatus. In this context, special attention will be devoted to the implications of the theory of chaos for economic analysis and prediction. Irregular motions in economics are seemingly more dominant nowadays than structural trajectories that are taken into account by means of conventional modeling.

In the paper various lessons from the theory of chaotic behaviour for economics will be drawn. It will be concluded that in various cases chaotic regimes are fairly esoteric which are not always based on plausible economic patterns, although on the other hand economic predictions would have to take stability patterns in the prediction domain more seriously than in the past.

These conclusions will be illustrated by means of two models, one describing a simple chaotic regime for economic development based on a quasi-production function approach, and another one representing a comprehensive economic system in which technological progress is a major driving force and in which diseconomies of scale and scope prevail.

These illustrations teach us the important lesson that in economics much more emphasis has to be laid upon specification analysis and validity tests of models vis-à-vis empirical facts.
\end{abstract}

\section{Prologue}

Economic modeling is - besides scientific insight - an important instrument in the economist's toolbox. And it is even a necessary tool for predicting complex (i.e., multicompartmental and dynamic) systems. However, prediction of a complex (evolutionary) economic system is a far from easy task, in particular if this system is characterized by structural changes in which also various system's parameters are fluctuating. The confidence in predictive models has certainly decreased in the past years, especially since the emerging popularity of principles from catastrophe and chaos theory. It is indeed true that under certain conditions predictions become less meaningful, especially in case of high growth rates in a bounded evolutionary system.

In this paper I will treat some elements from evolutionary dynamics and illustrate some points by means of possible evolutionary trajectories of an economic system, based on simple assumptions on its production technology. It appears that in case of stable development, conventional prediction tools may still be valid. The lesson from our exposition is that much more attention would have to be given by economists to (i) conditions governing dynamics of a system, and (ii) specification of basic dynamic reaction models. 


\section{Non-linear Dynamics : Stable or Chaotic Evolution}

The design of predictive models has already a long history in economics. And many countries are able to show a remarkable performance in building and applying such models. Nevertheless, it is increasingly recognized that in an unstable environment our analytical apparatus may fail. The oil crisis and-more recently-'black Monday' provides us with convincing illustrations of shortcomings in our toolbox.

Two observations have to be made at the outset. The time span of economic prediction models is critical for its success. Quarterly or monthly predictions are usually more difficult than average predictions on an annual basis. The upswing and downswing of exchange rates on the capital or stock market on a daily basis fluctuate so much that even a sophisticated model is unable to generate meaningful predictions, but the average annual growth rate is easier to predict. Essentially the same conclusion applies to other disciplines, such as sociology or meteorology. Another observation concerns the level of analysis of the predictive model. For a large-sale system the fluctuations are in general much less significant than for a micro-unit of the system, as we also know from entropy theory. Thus predictions for individuals tend to be more unreliable than those for aggregates.

There is no doubt that-despite an impressive level of sophistication-most economic prediction models are plagued by one basic feature, viz. linear comparative statics. Such models may lead to reliable results in a stable evolution of an economic system (in particular, if we focus on a short-term horizon), but are bound to lead to false predictions in case of unstable evolution.

It is evident that any comparative static approach presupposes some sort of dynamics. For example, in Samuelson's correspondence principle it is taken for granted that the dynamic adjustment process through which equilibrium is restored after an initial perturbation is stable. Besides, a linear model will always generate a stable equilibrium, so that in that case noncyclic fluctuations and bifurcations can only be generated by means of stochastic processes (cf. Brocker 1986, and Schuster 1984).

In the recent past, various new mathematical tools have been developed in order to cope with the issue of non-linear dynamics. Examples are bifurcation theory, catastrophe theory, singularity theory, fractal theory and chaos theory. Especially in the natural sciences there is a growing awareness of limitations inherent in static linear models. Here the attention has increasingly shifted from point predictions towards transitions (or bifurcations) in a complex dynamic system, with a particular view on the driving forces (or conditions) governing such transitions.

Non-linear dynamic relationships in economics are certainly not an unknown phenomenon (at least not in theoretical economics), but in most empirical applications linear (or linearized) models still abound, one important reason being that non-linear dynamic econometrics is by no means a well developed field of research and another one that specification theory is still a weak part in economic modeling (see Blommestein, 1986). It 
is noteworthy that the issue of non-linear dynamics in economic modeling is not related to stochastic properties of the system, but only to the way synchronic and diachronic processes are intertwined (see also Lichtenberg and Lieberman, 1983, and Liossatos, 1980). Under certain conditions discontinuities in a system's behaviour may then emerge, which reflects essentially a morphogenesis in the evolution of the system concerned. Morphogenesis may be based on either endogenous forces (e.g., behavioural feedbacks), or exogenous forces (e.g., in case of random shock models or ceilings and floors models) or a combination of both (e.g., regime switching models).

An important characteristic of current economic dynamics is its complex, multidimensional and nested structure. Due to large fluctuations caused by dissipative structures, economies of various countries or regions may become unstable and even exhibit bifurcations (see Turner, 1980). In particular, if various subsystems within an economy (for instance, industry, infrastructure, ect.) are intertwined in a non-linear dynamic way (sometimes even with differences in the successive rates of change), unexpected switches in evolutionary patterns may take place (see also Haag and Weidlich, 1983).

In recent years, a wide variety of dynamic economic models for countries and regions has been developed. Surprisingly enough, only a limited number of these studies exhibited structural dynamics (see, for instance, for a survey on spatial models Nijkamp et al., 1985). A major analytical problem in this respect is the question whether structural changes are caused by intra-systemic (endogenous) devolopments or exogenous forces (external to the system). This problem runs parallel to the current scientific debate on the existence of long waves in economics, where especially the Schumpeterian viewpoint regarding the endogenety of phases in a Kondratieff long wave is being tested (see also Kleinknecht, 1986). Due to lack of long time series data this proposition is difficult to validate.

Consequently, a meaningful model for analyzing and predicting structural dynamics of an economic system should be able to generate various trajectories for the evolution of the system, in which both endogenous and exogenous fluctuating patterns may play a role. Furthermore, such a model may lead to testable hypotheses in order to explore under which conditions a certain stable or unstable growth path for an economic system may emerge. In recent years, this has led to the popularity of the theory of chaos, especially since this new research line is focusing attention on the motives and trajectories of dynamic evolution.

Informative surveys of chaos theory and its relevance for the social sciences can also be found in contributions by Anderson (1988), Benhabib and Day (1981, 1982), Boldrin (1988), Devaney (1986), Guckenheimer and Holmes (1983), Kelsey (1988), Lasota and Mackey (1985), Lung (1988), Pohjola (1981), Prigogine and Stengers (1985), Stewart (1989), and Stutzer (1980).

The new logic which has emerged in the area of non-linear dynamics by the introduction of the theory of chaos has also interesting psychological features ; to some extent the popularity of chaos theory is caused by the fact that model builders need not necessarily be blamed anymore for false predictions; errors in predictions may be a result of the 
system's complexity, as can be demonstrated by examining more carefully the properties of the underlying non-linear dynamic model. In this case particular model specifications are in fact used to conceal the modeler's inability to make proper predictions! A fact is that chaos theory is currently regarded as a major discovery with a high significance for both the natural and social sciences.

The theory of chaos deals essentially with deterministic, non-linear dynamic systems which are able to produce complex motions of such a nature that they are sometimes seemingly random. In particular, they incorporate the feature that small uncertainties may grow exponentially (although all time paths are bounded), leading to a broad spectrum of different trajectories in the long run, so that precise or plausible predictions are-under certain conditions-almost impossible.

After a series of interesting studies on chaotic features of complex systems in physics, chemistry, biology, meteorology and ecology, chaos theory has also been introduced and investigated in the field of economics and geography. The main purpose of the use of this theory in the social sciences was to obtain better insight into the underlying causes of unforeseeable evolutions of complex systems.

- A main feature of the great many applications of chaos theory in the social sciences is their lack of empirical content, a major reason being that most applications focus on the macro system's level, for which in general long time series (including structural changes) are not available. At the individual level only a few attempts have been made, among others by Albin (1987) in the area of competitive interactions between individual firms and by Nijkamp and Reggiani (1990) in the area of dynamic discrete choice modelling based on a micro utility function for spatial choice alternatives (e.g., in residential choice of route choice problems).

In recent years, we have seen in economics an increasing wave of contributions in the use of chaos theory for analyzing economic dynamics. It is noteworthy that already in the 1960 's an interesting application of chaos theory to economics was provided by Goodwin, who studied economic dynamics by means of an accelerator-multiplier framework for persistent, deterministic oscillations as an endogenous results of a dynamic economic system (see for a survey Goodwin, 1982). But only recently the awareness has grown that deterministic (periodic or a-periodic) fluctuations (or even bifurcations and jumps) in a complex dynamic economic system may be the result of small perturbations. Unexpected behaviour of non-linear dynamic models leads to the question of validity of model specifications (i.e., are model specifications compatible with plausible economic hypotheses) and of testability of model results (i.e., are model results-qualitatively or quantitatively-justifiable from possible non-linear patterns in the underlying data set). Further expositions on these issues can be found amongst others in Baumol and Benhabib (1989), Baumol and Quandt (1985), Chen (1988), Kelsey (1988) and Lorenz (1989). Applications and illustrations of chaos theory in economics can be found inter alia in the following fields :

- growth and business cycle theory (Balducci et al. 1984 ; Benhabib and Day 1982 ; Boldrin 1988 ; Day 1982 ; Funke 1987 ; Guckenheimer et al. 1977 ; Grandmont 1985, 
1986 ; Stutzer 1980).

- cobweb models (Chiarella 1988)

- long waves analysis (Nijkamp 1987 ; Rasmussen et al. 1985 ; Sterman 1985)

- R \& D analysis (Baumol and Wolff 1983; Nijkamp and Poot 1989)

- consumer behaviour (Benhabib and Day 1981)

- duopoly theory (Rand 1978; Dana and Montrucchio 1986)

- economic competition (Deneckere and Pelikan 1986; Ricci 1985)

- international trade (Lorenz 1987)

Interesting applications of chaos theory to related branches of economics can be found in geography and regional science (see also Nijkamp and Reggiani, 1989). Examples are :

- regional industrial evolution (White 1985)

- urban macro dynamics (Dendrinos 1984)

- spatial employment growth (Dendrinos 1986)

- relative population dynamics (Dendrinos and Sonis 1987)

- spatial competition and innovation diffusion (Sonis 1986, 1988)

- migration systems (Reiner et al. 1986)

- urban evolution (Nijkamp and Reggiani 1988)

In this paper we will illustrate the use and relevance of chaos theory by developing two related examples, one in the area of economic development analysis (Section 2) and another one in the area of economic evolution based on innovation and R \& D (Section 3). In both cases it will be shown that in case of reasonable growth rates stable behaviour may emerge, but that in case of high growth suddenly unexpected fluctuations may emerge.

\section{A Simple Model for Evolutionary Economic Development}

It is usually taken for granted that a proper combination of conventional productive resources and public overhead capital (including $R \& D$ ) is a necessary condition for balanced growth. These factors are essentially the propulsive motives and incubators for the process of structural economic developments (see also Rosenberg 1976). It has already been mentioned that in case of qualitative changes in a non-linear dynamic system (e.g., a city or region) several shocks and perturbations may emerge (see for spatial illustrations also Allen and Sanglier 1979 ; Casetti 1981 ; Dendrinos 1981 ; and Wilson 1981). A simple mathematical representation of the driving forces of such a spatial system can be found in Nijkamp $(1983,1984,1989)$. This simplified model was based on a so-called quasi-production function (including productive capital, infrastructure and R \& D capital as arguments). The dynamics of the system was described by motion equations for productive investments, infrastructure investments and R \& D investments. Several constraints (i.e., ceilings) were also added, for instance, due to the existence of capacity limits.

In the present paper we will start with a simple one-country dynamic neo-classical production function as the basis for a more formal analysis of growth patterns of an economy. The assumption is made that output is generated by a mix of conventional production factors (capital, labour) and public overhead capital (including R \& D capital). 
Later on we will turn to a more complicated and comprehensive economic system (Section 3 ) and also analyse the stability properties of this system.

In this section, the following generalized production function will be assumed for a (closed) economic system :

$$
Y=f(Q, P)
$$

with $Y, Q$ and $P$ representing output, conventional production factors and social overhead capital, respectively. If a normal Cobb-Douglas specification is assumed, one may write (2.1) as follows :

$$
Y=\alpha Q^{\beta} P^{\gamma}
$$

where the parameters $\beta$ and $\gamma$ reflect the production elasticities concerned. It should be noted that, if instead of social overhead and $\mathrm{R} \& \mathrm{D}$ capital an exponential growth rate of technological progress would have been included in (2.2), the resulting Cobb-Douglas production function would have been at the same time Harrod-, Hicks- and Solow-neutral, provided the technical change concerned would have been disembodied (see Stoneman 1983).

Production function (2.2) is assumed to be a reasonable approximation of the underlying production technology within a range of realistic floors and ceilings $\left(Y_{\min }, Y_{\max }\right)$. Only on this range the production elasticities are assumed to be strictly positive. It is known from the literature that the existence of either floors or ceilings may generate fluctuating patterns. Beyond the minimum threshold level $Y_{\min }$, the critical mass of the economy may be too small to generate economies of scale and scope, so that then a marginal increase in one of the production factors may have a negligible impact on the production output. This situation indicates that an economy needs a minimum endowment with production factors before it reaches a self-sustained growth path.

Besides, beyond a certain maximum capacity level $Y_{\max }$ of the economy, bottleneck phenomena (congestion, diseconomies of scale of scope, e.g.) caused by a high concentration of $Q$-may lead to a zero or even negative marginal product of conventional production factors, affecting the economies of scale negatively. Then any further increase in these production factors may affect output, unless this situation of a negative marginal product is compensated and corrected by the implementation of new public overhead and R \& D investments (the 'depression trigger' phenomenon).

If model (2.2) is explicitly put in a dynamic form, then within the relevant range ( $Y_{\text {min, }}$, $\left.Y_{\max }\right)$ the changes in output in a certain period of time may be approximated by means of the following discrete time version of (2.2):

$$
\Delta Y_{t}=\left(\beta q_{t}+\gamma p_{t}\right) Y_{t-1},
$$

with :

$$
\Delta Y_{t}=Y_{t}-Y_{t-1}
$$

and : 


$$
\begin{aligned}
& q_{t}=\left(Q_{t}-Q_{t-1}\right) / Q_{t-1} \\
& p_{t}=\left(P_{t}-P_{t-1}\right) / P_{t-1}
\end{aligned}
$$

Thus the production factors are now included as relative changes in the dynamic model (2.2). Such a discrete approximation of a model with a continuous time trajectory is valid within the range for which the structure of the economic system is stable. Within this range the system will exhibit a non-cyclical growth. This self-sustained growth path may be drawing to a close due to two causes :

- external : scarcity of production factors or lack of demand

- internal: emergence of diseconomies of scale and scope leading to negative marginal products.

External factors will only imply that the system will move toward an upper limit set by the constraint concerned. Internal factors may lead to perturbations and qualitative changes in systemic behaviour. Suppose for instance, a congestion effect caused by too high a concentration of capital in an economic system. Then each additional increase in productive capital will have a negative impact on output. This implies that the production elasticity has become a negative time-dependent variable. In other words, beyond the capacity limit $Y_{\max }$ an auxiliary relationship reflecting a negative marginal product of conventional production factors may be assumed:

$$
\beta_{t}=\hat{\beta}\left(Y_{\max }-\varkappa Y_{t-1}\right) / Y_{\max },
$$

where $x$ is a standerdisation coefficient for the discrepancy function. Substitution of (2.6) into (2.3) leads to the following adjusted dynamic production function :

$$
\Delta Y_{t}=\hat{\beta} q_{t}\left(Y_{\max }-x Y_{t-1}\right) Y_{t-1} / Y_{\max }+\gamma p_{t} Y_{t-1}
$$

This is seemingly a fairly simple non-stochastic dynamic relationship, but it can be shown that this equation is able to generate unstable and even erratic behaviour leading to aperiodic fluctuations. The standard format of (2.7) can be written as follows:

$$
\Delta Y_{t}=v_{t}\left(Y_{\max }-\chi Y_{t-1}\right) Y_{t-1} / Y_{\max }+\gamma p_{t} Y_{t-1}
$$

with :

$$
v_{t}=\hat{\beta} q_{t}
$$

The latter relationship is essentially nothing else but the growth rate of output generated by the new technological conditions reflected in the production elasticity $\hat{\beta}$. Usually such a relative change is positive but smaller than 1 . If the Cobb-Douglas function is homogeneous of degree one, it is thus plausible to stipulate that only in case of drastic or structural changes $v_{t}$ is larger than 1 . But even if the degree of homogeneity would be higher than 1 , the expression at the right-hand side of (2.9) would be relatively small, as in case of a normal evolutionary pattern the relative changes in production factors will not be excessively high. Thus the parameters of the above model can in fact be classified according to stable or non-stable (e.g., turbulent) behaviour.

It is noteworthy that equation (2.8) is essentially a part of a Volterra-Lotka type 
model which has in recent years often been used for modelling predator-prey relationships in population dynamics (see also Goh and Jennings 1977 ; Jeffries 1979 ; Pimm 1982 ; and Wilson 1981). This model in difference equation form has been dealt with among others by May (1974), Li and Yorke (1975) and Yorke and Yorke (1975). Applications in a geographical setting can be found in Brouwer and Nijkamp (1985), Dendrinos and Mullally (1983, 1984) and Nijkamp and Reggiani (1989) among others. In the present context, the dynamic trajectory of the economy can be studied more precisely by rewriting (2.8) as :

$$
\Delta Y_{t}=v_{t}\left(1-\varkappa Y_{t-1} / Y_{\max }\right) Y_{t-1}+\gamma p_{t} Y_{t-1}
$$

Equation (2.10) is a standard equation from population dynamics. It should be noted that logistic evolutionary patterns may also be approximated by a (slightly more flexible) Ricker curve (see May 1974). In that case, the exponential specification precludes the generation of negative values for the $Y$ variables in simulation experiments, a situation that may emerge in relation to equation (2.10). Model (2.10) has some very unusual properties. On the basis of numerical experiments, it was demonstrated by May that this model may exhibit a remarkable spectrum of dynamical behaviour, such as stable equilibrium points, stable cyclic oscillations, stable cycles, and chaotic regimes with aperiodic but bounded fluctuations. Two major elements determine the stability properties of $(2.10)$, viz. the initial values of $Y_{t}$ and the growth rate for the economic system (which is depending on $v_{t}$ ). Simulation experiments indicated that especially the growth rate has a major impact on the emergence of cyclic or a-periodic fluctuations.

May has also demonstrated that a stable equilibrium may emerge if the growth rate satisfies the condition: $0 \leq v_{t} \leq 2$; otherwise stable cyclic and unstable fluctuations may be generated. Li and Yorke (1975) have later developed a set of sufficient conditions for the emergence of chaotic behaviour for general continuous difference equations. Clearly, in a discrete model the potential chaotic behaviour depends on the value of $v_{t}$. As indicated above, especially in case of incremental changes $v_{t} \leq 1$, so that then a stable equilibrium is ensured; otherwise many alternative evolutionary patterns of the system concerned may emerge. Consequently, the conclusion may be drawn that-due to the presence of a capacity limit $Y_{\max }$-an economy might in principle exhibit a wide variety of dynamical or even cyclical growth patterns.

Clearly, in our case there is a difference with respect to May's model. In May's model, $v$ is a constant, whereas in our case $v$ is endogenously determined by the evolution of our economic system (see equation (2.9)). This has clearly an effect on the growth trajectory, but-given the conditions on $v_{t}$-this does not affect the main conclusions regarding the stability of the system, although it has to be realized that drastic changes in a previous period are likely to generate perturbations in the next period. Since the growth rate $v_{t}$ is not necessarily a constant, it may become an endogenous variable which may be used as a control variable in order to generate a more stable growth path.

In order to show the possible varieties of system's behaviour of the above mentioned model, we will present the results of two simple simulation experiments. The first 


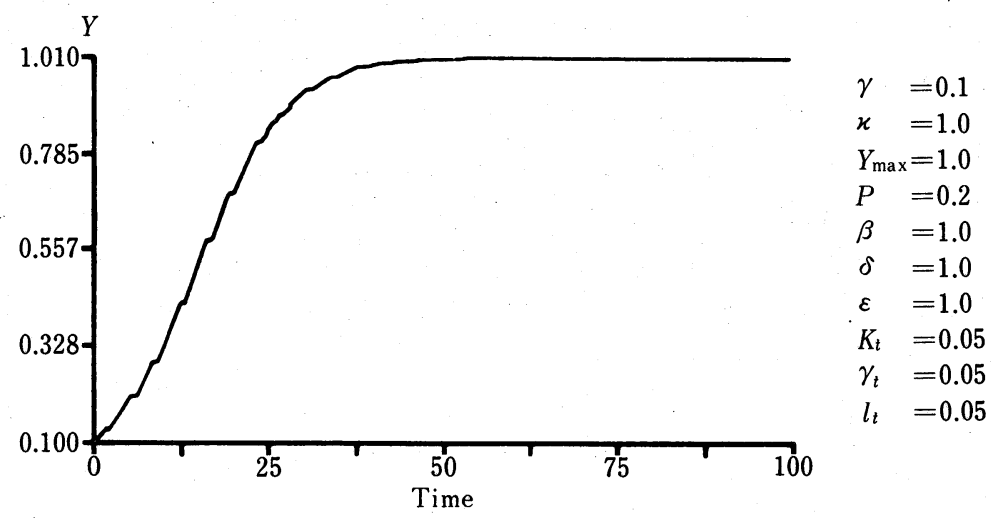

Figure 1 Results of a simulation run for stable growth.

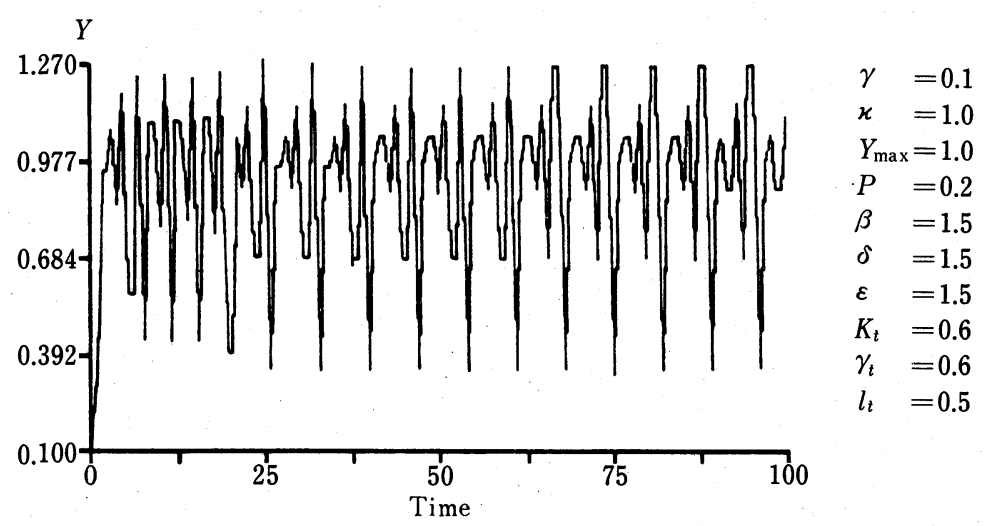

Figure 2 Results of a simulation run for unstable growth.

simulation will be based on very modest growth rates of our dynamic system which will lead to stable equilibrium (see Figure 1).

The second run takes for granted extremely high growth rates so that system's boundaries are rapidly reached. In that case wild fluctuations may occur which are of a chaotic type (see Figure 2).

It is evident that the plausibility of such results depends on the specification of the model, the initial conditions of the variables and the critical values of model parameters. This is of course a matter of further empirical tests of our model in a real world situation.

Finally, it should be noted that the basic model from Section 2 can be extended in various ways, inter alia by including endogenous $R \& D$ investments and exclusion constraints associated with diffusion of innovation. The elaboration of these ideas can be found in Nijkamp (1989).

\section{A Dynamic Model for Innovation and Diseconomies of Scale}

In Section 2 a simple model for a growing production system facing the limits to 
growth has been analyzed, with particular emphasis on the role of conventional production factors vis-à-vis social overhead capital. In the present Section we will elaborate on this by presenting a model for the analysis of $\mathrm{R} \& \mathrm{D}$ impacts on the elimination of boundaries in a constrained economy. Particular attention will again be given to stability properties.

Technological change has become a focal point in current evolutionary economics (cf. Nelson and Winter 1982). For an open economic system also interesting research has been pursued, among others by Andersen (1989) who developed a simulation model for a two region economy. In most analyses, $\mathrm{R} \& \mathrm{D}$ plays a crucial role in enhancing the efficiency and the competitive position of firms or countries.

In general, $\mathrm{R} \& \mathrm{D}$ expenditures generate, like investment in conventional capital goods, an intertemporal allocation problem : more R \& D efforts may lead to a higher long-run productivity and profitability, but requires lower short-run consumption, and vice versa. This choice problem for capital formation has been extensively studied in traditional growth theory, both for economies on a steady state growth path ('golden rule of accumulation') and in the framework of an intertemporal welfare optimisation problem (by means of optimal control theory); see also Rasmanathan (1982).

In this respect, two important questions emerge. The first one refers to the behaviour of the growth path of the economy in an integrated consumption, production, investment and R \& D system, in particular when the system is facing capacity limits (e.g., congestion, other diseconomies of scale, or depletion of exhaustible resources). The second question is related to the interregional or international $\mathbf{R} \& \mathbf{D}$ specialisation and generates an interesting choice problem in that new technology in any region or nation may be obtained by $\mathrm{R} \& \mathrm{D}$ internally, or by acquiring it from external sources.

In this section, based on Nijkamp and Poot (1989), we shall explore the long-run evolutionary path of an economy by means of a dynamic (discrete-time) model incorporating the generation of technological change under conditions of diseconomies of scale. It will be shown that this system can also generate a wide range of dynamic behaviour, including-for certain parameters-a chaotic evolution. In the next section we will pay attention to technology transfer. We commence with the assumption that the economy under consideration is operating under the following production function regime:

$$
Y_{t}=\epsilon_{t} K_{t}
$$

where $K_{t}$ is the installed capital stock at the beginning period $t$ and $\epsilon_{t}$ is a technological coefficient representing average capital productivity during the period $(t=1, t)$. This linearity assumption is not as restrictive as it seems, since in a sense we may consider (3.1) an identity in which $\epsilon_{t}$ includes all factors (labour, land, social overhead capital, R \& D) which influence capital productivity. Consequently, the elasticity of substitution between capital and other production factors is not assumed to be zero; the time trajectory of $\epsilon$ can incorporate both movements along the production frontier as well as shifts in this frontier.

It is clear that the following condition holds for capital accumulation :

$$
K_{t+1}=(1-\delta) K_{t}+I_{t}
$$


where $I_{t}$ stands for gross investment during period $(t, t+1)$ and $\delta$ is the rate of physical depreciation of the capital stock. The following simple investment function is assumed:

$$
I_{t}=\sigma_{1} Y_{t}
$$

where $\sigma_{1}$ is the fixed average savings rate (assuming the existence of equilibrium between savings and capital increase). Clearly, $\sigma_{1}$ may act as one of the control parameters of our dynamic system.

Given a macroeconomic equilibrium for investment and savings, i.e.,

$$
Y_{t}=C_{t}+I_{t}
$$

we can easily derive that consumption $C_{t}$ is equal to:

$$
C_{t}=\left(1-\sigma_{1}\right) Y_{t}
$$

It is evident that the current production efficiency can be increased through $\mathrm{R} \& \mathrm{D}$ embodied in the production technology. Then the production function has to be extended, as R \& D investments will increase efficiency due to a change in the capital coefficient (see Baumol and Wolff, 1984 ; Mansifield, 1980 ; Nelson, 1981). Thus, in order to shape a new 'technological regime' (cf. Nelson and Winter, 1982), R \& D expenditures with a positive impact on the production efficiency parameter $\epsilon_{t}$ will be necessary. This effect may be represented by a parameter $\nu_{t}$, which measures the impact on capital productivity as a result of a unit of $\mathrm{R} \& \mathrm{D}$ expenditures. Then we have :

$$
\Delta \epsilon_{t}=\epsilon_{t+1}-\epsilon_{t}=\nu_{t} R_{t}
$$

where $R_{t}$ represents the $\mathrm{R} \& \mathrm{D}$ investments during period $(t, t+1)$ and $\nu_{t}$ the $\mathrm{R} \& \mathrm{D}$ impact coefficient for the capital coefficient. Now we have to introduce a relationship for $R_{t}$, which defines the savings rate for $\mathrm{R} \& \mathrm{D}$ in a way analogous to (3.3):

$$
R_{t}=\sigma_{2} Y_{t}
$$

so that the consumption is then equal to:

$$
C_{t}=\left(1-\sigma_{1}-\sigma_{2}\right) Y_{t}
$$

Substitution of (3.7) in (3.6) givies :

$$
\Delta \epsilon_{t}=\nu_{t} \sigma_{2} Y_{t}
$$

When $\nu_{t}$ were constant over time, capital accumulation would generate ever-increasing growth in output and capital productivity. This highly unlikely outcome indicates that $\nu_{t}$ is likely to decrease when output increases. In other words, the marginal efficiency of $\mathrm{R} \& \mathrm{D}$ declines when production rises. Under a given 'technological regime', ultimately a 'saturation' level of output $Y_{t \text {, max }}$ is likely to exist at which additional R \& D has no longer an impact on productivity. Such a saturation level (ceiling) may arise from capacity limits (technological, social, economic) and reflects-for a given production technology-a 'limits to growth' phenomenon, stemming from diseconomies of scale and scope (see also Section 2). Arguments in favour of the assumption of a decreasing productivity of $\mathrm{R} \& \mathrm{D}$ in case of 
more mature economic conditions can also be found in Ayres (1987) and Metcalfe (1981).

In view of the above observations it is now clear that $\nu_{t}=0$ when $Y_{t} \geq Y_{t \text {,max }}$. Naturally, these limits to growth themselves may be subject to change, so that $Y_{t, \max }$ may increase with time and-as prevailing bottlenecks are overcome-new R \& D again have a positive effect on productivity. Thus, the following specification for an adjusted (i.e., timedependent) R \& D impact parameter seems plausible :

$$
\nu_{t}=\max \left\{\nu^{*},\left(1-Y_{t} / Y_{t, \max }\right), 0\right\}
$$

This kinked curve is depicted in Figure 3. An analogous result might also be reached by imposing a saturation level for $\epsilon_{t}$.

In addition, it is plausible that not only would $\mathrm{R} \& \mathrm{D}$ expenditure become ineffective if output expands beyond $Y_{t, \max }$, but it may also be expected that diseconomies of scale and scope set in which reduce capital productivity. The previous remarks indicate that instead of (3.6) we may now have the following simple relationship:

$$
\Delta \epsilon_{t}=\nu_{t} R_{t}-\mu_{t} Y_{t}
$$

in which $\mu_{t}$ measures the effect of diseconomies on productivity when output exceeds $Y_{t, \max }$, so that:

$$
\mu_{t}=\max \left(\mu^{*}\left(Y_{t} / Y_{t, \max }-1\right), 0\right)
$$

By substituting (3.12) and (3.10) into (3.6) and recalling (3.1) and (3.2), the motion in the system can now be described by the following set of non-linear difference equations:

$$
\begin{aligned}
K_{t+1} & =(1-\delta) K_{t}+\sigma_{1} \epsilon_{t} K_{t} \\
\epsilon_{t+1} & =\epsilon_{t}+\left[\sigma_{2} \nu^{*} \max \left(1-Y_{t} / Y_{t, \max }, 0\right)-\mu^{*} \max \left(Y_{t} / Y_{t, \max }-1,0\right)\right] \epsilon_{t} K_{t} \\
Y_{t+1} & =\epsilon_{t+1} K_{t+1}
\end{aligned}
$$

In view of the chaotic properties of our model, it is clear that for any given initialisation $\left(K_{0}, G_{0}, Y_{0}, Y_{0, \max }\right)$ system (3.13)-(3.15) can exhibit a wide range of time trajectories dependent on parameter values.

Some results based on simulation experiments are illustrated in Figures 4 and 5.

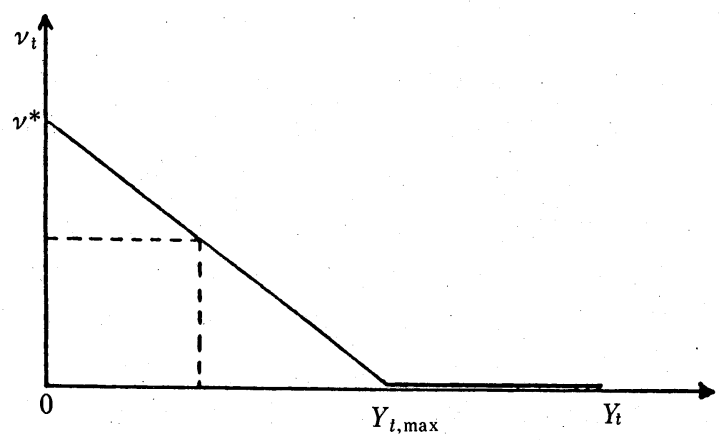

Figure 3 Decreasing marginal benefits of $\mathrm{R} \& \mathrm{D}$ expenditures. 
Figure 4 is based on the assumption that $K_{0}=1000$ and the capital-output ratio equals 5 ; hence $\epsilon_{0}=0.2$ and $Y_{0}=200$. The saving ratio is 20 percent ; 2 percent of the capital stock is assumed to become obsolete each period and 2 percent of income is spent on R \& $D$, so that $\sigma_{1}=0.20$ and $\delta=\sigma_{2}=0.02$. The sustainable output capacity $Y_{0, \max }=1000$ and grows at 1 percent. Moreover, $\mu^{*}=0.0001$ and $\nu^{*}=0.001$. Since $5 \sigma_{2} \nu^{*}=\mu^{*}$, the productivity response is five times as elastic when $Y_{t}>Y_{t, \max }$ than when $Y_{t}<Y_{t, \max }$, and of opposite sign. Clearly, $Y_{t, \max }$ is given for all periods.

Now, Figure 4 shows that growth in the system is-under these conditions-in initial periods accelerating. However, the growth rate of capital productivity reaches a maximum at $t=25$ and subsequently declines, until $Y_{t}$ reaches the saturation level $Y_{t, \max }$ at $t=$

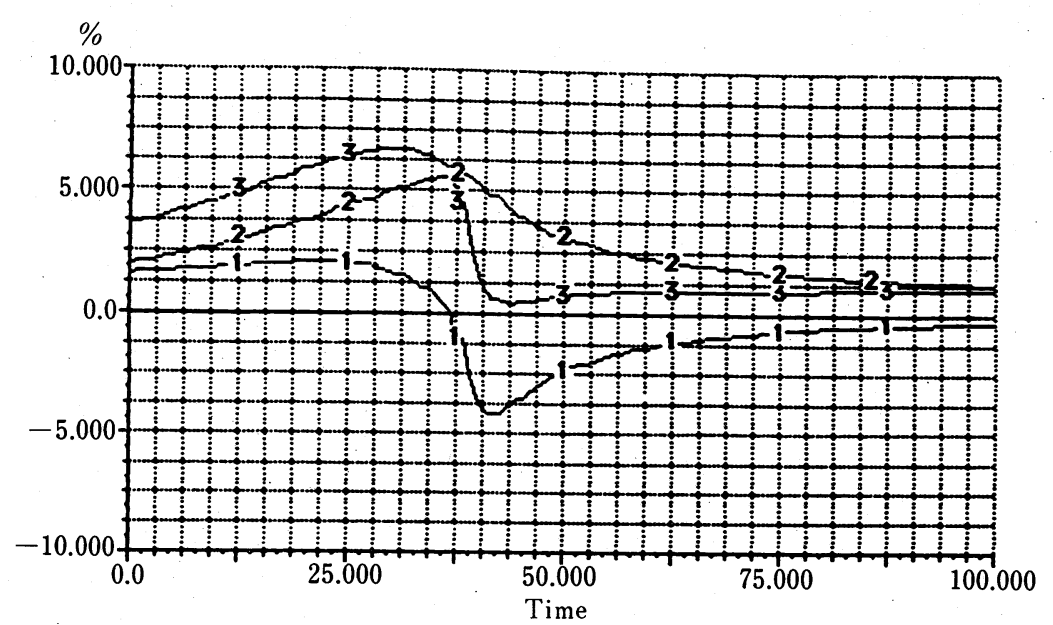

Figure 4 Growth converging to a steady state. 1 : growth in capital productivity, 2 : capital growth rate, 3 : income growth rate.

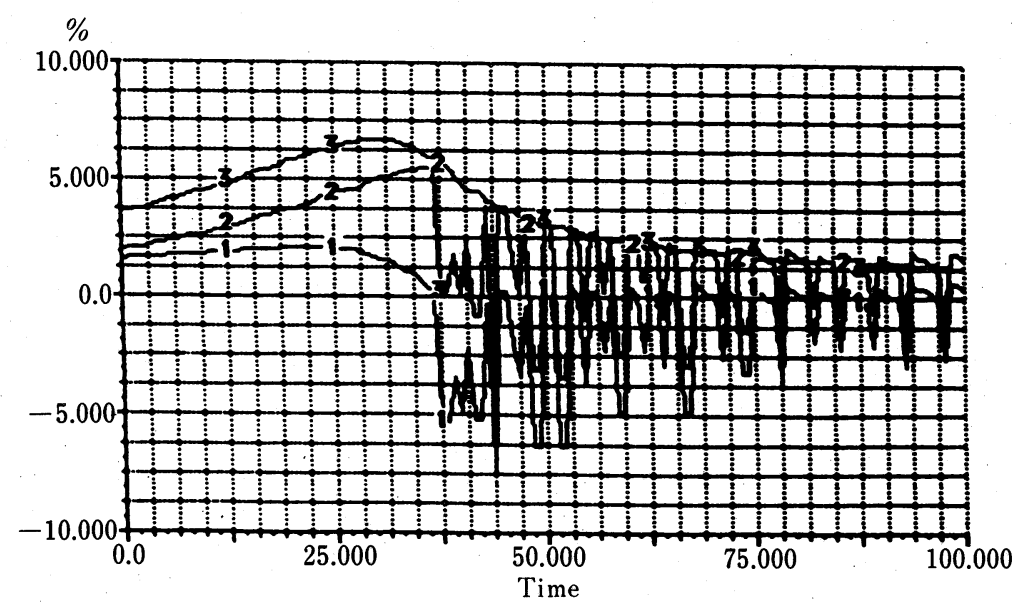

Figure 5 Growth cycles generated by strong external diseconomies. 
37. At this point, the growth rate of capital accumulation reaches a maximum. Beyond $t=37, Y_{t}$ will remain above $Y_{t, \max }$ but it will converge to the latter value. Consequently, capital productivity becomes constant at a rate of $(n+\delta) / \sigma_{1}=0.15$, whilst capital and output grow at a steady state rate of 1 percent.

Next, we assume that in Figure 5 all parameters are the same as in Figure 4, but $\mu^{*}$ has been increased to five times its former value. Consequently, the effect of diseconomies is now sufficiently strong to push $Y_{t}$ at times below $Y_{t, \max }$ so that growth cycles are generated with a variable periodicity but with decreasing amplitude. The system eventually converges again to a steady-state growth of 1 percent. Thus this is a nice example of a self-organizing system.

The models presented in Sections 2 and 3 were essentially non-spatial in nature; they took for granted the existence of a single (closed) economy. In a system of regions (or countries), technology transfers between regions may increase the $\mathrm{R} \& \mathrm{D}$ efficiency in some or all regions (see also Kamien and Schwartz, 1982, Nijkamp, 1985, and Scherer, 1980). Interregional spill-overs of $\mathrm{R} \& \mathrm{D}$ efforts might then be introduced by means of a spatial R \& D transfer function. Further details on this approach can be found in Nijkamp and Poot (1989).

\section{Retrospect}

If instead of a simulation experiment, one would have to use models of the above nature as normative policy models, it would be necessary to introduce an appropriate objective (or welfare) function encompassing a trade-off between relevant welfare arguments. A dynamic programming or optimal control formulation would then be desirable (see Kendrick, 1981, and Nijkamp and Reggiani, 1988, 1989). Such a constrained dynamic optimization might in principle reduce chaotic fluctuations inherent in the nonlinear dynamics of an interdependent multiregional growth system.

Another point concerns the specification of non-linear dynamic models. It may be important to stress that the foundations of specifying an economic model have to be firmly rooted in economic theory, as otherwise we run the danger of ad hoc and mis-specifications, which may create chaotic behaviour that is not based on plausible economic grounds.

Finally, it is important to call attention to the fact that in various cases a system is not chaotic as a whole, but has only a few 'niches' (modules or equations) which under certain conditions may exhibit chaotic behaviour. The question whether chaotic behaviour of a small sub-system will be dampened by the dominance of another and other-wise stable system, or whether it will exert an explosive influence upon a whole system needs further investigation.

Although non-linear models for interregional competitive behaviour may provide an interesting explanatory framework for the rise and decline of regions in a dynamic (sometimes chaotic) context, it is also evident from the above experiences that the 'economics of chaos' desparately needs rigorous empirical research work. 


\section{References}

[1] Albin, P.S., Microeconomic Foundations of Cyclical Irregularities or Chaos, Mathematical Social Sciences, vol. 13, 1987, pp. 185-214.

[2 ] Allen, P.M. and M. Sanglier, A Dynamic Model of Growth in Central Place System, Geographical Analysis, vol. 11, 1979, pp. 256-272.

[ 3 ] Andersen, D.F. (ed.), Chaos in System Dynamic Models: Special Issue System Dynamics Review, vol. 4 , no. $1 / 2,1988$.

[4 ] Andersen, W.P., An Evolutionary Model of Growth in a Two Region Economy, The Annals of Regional Science, vol. 23, no. 2, 1988, pp. 105-121.

[5] Ayres, R.U., Barriers and Breakthroughs: An "Expanding Frontiers" Model of the TechnologyIndustry Life Cycle, Research Paper, IIASA, Laxenburg, 1987.

[6] Balducci, R.G. Candela and G. Ricci, A Generalization of R. Goodwin's Model with Rational Behaviour of Economic Agents, Nonlinear Models of Fluctuating Growth, (R.M. Goodwin, M. Krüger and A. Vercelli, eds.), Springer-Verlag, Berlin, 1987, pp. 47-66.

[ 7 ] Baumol, W.J. and E.N. Wolff, Feedback from Productivity Growth in R \& D, Scandinavian Journal of Economics, vol. 85, 1983, pp. 145-157.

[ 8 ] Baumol, W.J. and E.N. Wolff, Feedback Models: R \& D Information, and Productivity Growth, Communication and Information Economics, (M. Jussawalla and H. Ebenfield, eds.), North-Holland Publ. Co., Amsterdam, 1984, pp. 73-92.

[ 9 ] Baumol, W.J. and J. Benhabib, Chaos: Significance, Mechanism, and Economic Applications, Journal of Economic Perspectives, vol. 3, no. 1, 1989, pp. 77-105.

[10] Baumol, W.J. and R.E. Quandt, Chaos Models and their Implications for Forecasting, Eastern Economic Journal, vol. 11, no. 1, 1985, pp. 3-15.

[11] Benhabib, J. and R.H. Day, Rational Choice and Erratic Behaviour, Review of Economic Studies, vol. 48, 1981, pp. 459-471.

[12] Benhabib, J. and R.H. Day, A Characterization of Erratic Dynamics in the Overlapping Generations Model, Journal of Economic Dynamics and Control, vol. 4, 1982, pp. 37-55.

[13] Blommestein, H.J., Eliminative Econometrics, Ph. D. Diss., Department of Economics, Free University, Amsterdam, 1986.

[14] Boldrin, M., Persistent Oscillations and Chaos in Dynamic Economic Models: Notes for a Survey, SFI Studies in the Science of Complexity, Addison-Wesley Publ. Co., 1988, pp. 49-75.

[15] Brocker, W.A., Distinguishing Random and Deterministic Systems, Journal of Economic Theory, vol. 40, 1986, pp. 168-195.

[16] Brouwer, F. and P. Nijkamp, Qualitative Structure Analysis of Complex Systems, Measuring the Unmeasurable; Analysis of Qualitative Spatial Data (P. Nijkamp, H. Leitner and N. Wrigley, eds.), Martinus Nijhoff, The Hague, 1985, pp. 509-532.

[17] Casetti, E., Technological Progress, Exploitation and Spatial Economic Growth: A Catastrophe Model, Dynamic Spatial Models (D.A. Griffith and R. MacKinnon, eds.), Sijthoff and Noordhoff, Alphen aan de Rijn, 1981, pp. 215-277.

[18] Chen, P., Empirical and Theoretical Evidence of Economic Chaos, System Dynamics Review, vol. 1, no. 1, 1988, pp. 81-108.

[19] Chiarella, C., The Cobweb Model : Its Instability and the Onset of Chaos, Economic Modelling, vol. 5, no. 4, 1988, pp. 377-384.

[20] Dana, R.A. and L. Montrucchio, Dynamic Complexity in Duopoly Games, Journal of Economic Theory, vol. 40, 1986, pp. 40-56. 
[21] Day, R.H., Irregular Growth Cycles, American Economic Review, vol. 72, 1982, pp. 406-414.

[22] Dendrions, D.S. (ed.), Dynamic Non-Linear Theory and General Urban/Regional Systems, School of Architecture and Urban Design, Lawrence, Kansas, 1981.

[23] Dendrions, D.S., Turbulence and Fundamental Urban/Regional Dynamics, Paper presented at the American Association of Geographers, Washington D.C., April 1984.

[24] Dendrinos, D.S., On the Incongruous Spatial Employment Dynamics, Technological Change, Employment and Spatial Dynamics, (P. Nijkamp, ed.), Springer-Verlag, Berlin, 1986, pp. 321-339.

[25] Dendrinos. D.S. and H. Mullally, Empirical Evidence of Volterra-Lotka Dynamics in United States Metropolitan Areas : 1940-1977, Evolving Geographical Structures (D.A. Griffith and T. Lea, eds.), Martinus Nijhoff, The Hague, 1983, pp. 170-195.

[26] Dendrinos, D.S. and H. Mullally, Urban Evolution, Oxford University Press, Cambridge, 1984.

[27] Dendrinos, D.S. and M. Sonis, The Onset of Turbulence in Discrete Relative Multiple Spatial Dynamics, Applied Mathematics and Computation, vol. 22, 1987, pp. 25-44.

[28] Deneckere, R. and S. Pelikan, Competitive Chaos, Journal of Economic Theory, vol. 40, 1986, pp. $13-25$.

[29] Devaney, R.L., Chaotic Dynamical Systems, Benjamin Cummings Publ. Co., Menlo Park, CA, 1986.

[30] Funke, M., A Generalized Goodwin Model Incorporating Technical Progress and Variable Prices, Economic Notes, vol. 2, 1987, pp. 36-47.

[31] Goh, B.S. and L.S. Jennings, Feasibility and Stability in Randomly Assembled Lotka-Volterra Models, Ecological Modelling, vol. 3, no. 1, 1977, pp. 63-71.

[32] Goodwin, R.M., Essays in Economic Dynamics, Macmillan, London, 1982.

[33] Grandmont, J.M., On Endogenous Competitive Business Cycles, Econometrica, vol. 53, 1985, pp. 995-1046.

[34] Grandmont, J.M. (ed.), Special Issue Journal of Economic Theory, vol. 40, 1986.

[35] Guckenheimer, J. and P. Holmes, Non-Linear Oscillations Dynamical System and Bifurcation of Vector Fields, Springer-Verlag, Berlin, 1983.

[36] Guckenheimer, J., G. Oster and A. Ipatchi, The Dynamics of the Density Dependent Population Models, Journal of Mathematical Biology, vol. 4, 1977, pp. 101-147.

[37] Haag, G. and W. Weidlich, A Nonlinear Dynamic Model for the Migration of Human Population, Evolving Geographical Structures (D.A. Griffith and T. Lea, eds.), Martinus Nijhoff, The Hague, 1983, pp. 24-61.

[38] Jeffries, C., Qualitative Stability and Digraphs in Model Ecosystems, Ecology, vol. 55, no. 6, 1979, pp. 1415-1419.

[39] Kelsey, D., The Economics of Chaos or the Chaos of Economics, Oxford Economic Papers, 40, 1988, pp. 1-31.

[40] Kleinknecht, A., Innovation Patterns in Crisis and Prosperity: Schumpeter's Long Cycle Reconsidered, MacMillan, London, 1986.

[41] Lasota, A. and M.C. Mackey, Probabilistic Properties of Deterministic Systems, Cambridge University Press, Cambridge, 1985.

[42] Li, T. and J.A. Yorke, Period Three Implies Chaos, American Mathematical Monthly, vol. 82, 1975, pp. 985-992.

[43] Lichtenberg, A.J. and M.A. Lickerman, Regular and Stochastic Motion, Springer-Verlag, Berlin, 1983.

[44] Liosattos, P., Spatial Dynamics: Some Conceptual and Mathematical Issues, Environment \& Planning A, vol. 12, 1980, pp. 1051-1071.

[45] Lorenz, H.W., International Trade and the Possible Occurrence of Chaos, Economics Letters, 
1987, vol. 23, pp. 135-138.

[46] Lorenz, H.W., Nonlinear Dynamical Economics and Chaotic Motion, Springer-Verlag, Berlin, 1989.

[47] Lung, Y., Complexity and Spatial Dynamics Modelling: From Catastrophic Theory to SelfOrganizing Process: a Review of Literature, The Annals of Regional Science, vol. 22, no. 2, 1988, pp. 81-111.

[48] Mansfield E., Industrial Research and Technological Innovation, W.W. Norton, New York, 1980.

[49] May, R.M., Biological Populations with Non-overlapping Generations, Science, no. 186, 1974, pp. 645-647.

[50] Metcalfe, J.S., Impulse and Diffusion in the Study of Technical Change, Futures, vol. 13, 1981, pp. 347-359.

[51] Nelson, R., Research and Productivity Growth and Productivity Differences, Journal of Economic Literature, vol. 8, 1981, pp. 1029-1064.

[52] Nelson, R.D. and S.G. Winter, An Evolutionary Theory of Economic Change, Harvard University Press, Cambridge, 1982.

[53] Nijkamp, P., Technological Change, Policy Response and Spatial Dynamics, Evolving Geographical Structures (D.A. Griffith and T. Lea, eds.), Martinus Nijhoff, The Hague, 1983, pp. 75-99.

[54] Nijkamp, P., A Multidimensional Analysis of Regional Infrastructure and Economic Development, Regional and Industrial Development Theories, Models and Empirical Evidence (A.E. Andersson, W. Isard and T. Puu, eds.), North-Holland Publ. Co., Amsterdam, 1984, pp. 267-293.

[55] Nijkamp, P., Employment, Technological Change and Spatial Dynamics, Springer Verlag, Berlin, 1986.

[56] Nijkamp, P., Long-Term Economic Fluctuations: A Spatial View, Socio-Economic Planning Sciences, vol. 21, no. 3; 1987, pp. 189-197.

[57] Nijkamp, P., Evolutionary Patterns of Urban Production Systems, Belgian Journal of Operations Research, Statistics and Computer Science, vol. 29, no. 2, 1989, pp. 23-40.

[58] Nijkamp, P. and J. Poot, A Nonlinear Dynamic Model of Spatial Economic Development and R \& D Policy, Research Memorandum, Dept. of Economics, Free University, Amsterdam, 1989.

[59] Nijkamp, P. and A. Reggiani, Dynamic Spatial Interaction Models: New Directions, Environment and Planning A, vol. 20, 1988, pp. 1449-1460.

[60] Nijkamp, P. and A. Reggiani, Theory of Chaos: Relevance for Analysing Spatial Processes, Spatial Choices and Processes, (M.M. Fischer, P. Nijkamp, and Y. Papageorgiou, eds.), NorthHolland Publ. Co., Amsterdam, 1989 (forthcoming).

[61] Nijkamp, P. and A. Reggiani, Logit Models and Chaotic Behaviour, Environmental and Planning A, 1990 (forthcoming).

[62] Nijkamp, P., A. Rima and L. van Wissen, Structural Change in Dynamic Urban Models, Spatial Mobility and Transportation in an Era of Transition (G.R.M. Jansen, P. Nijkamp and C. Rujigrok, eds.), North-Holland Publ. Co., Amsterdam, 1984, pp. 121-140.

[63] Kimm, S.L., Food Webs, Chapman and Hall, London, 1982.

[64] Pohjola, M.T., Stable and Chaotic Growth: the Dynamics of a Discrete Version of Goodwin's Growth Cycle Model, Zeitschrift für Nationalökonomie, vol. 41, 1981, pp. 27-38.

[65] Prigogine, I. and I. Stengers, Order out of Chaos, Fontana, London, 1985.

[66] Rand, D., Exotic Phenomena in Games and Duopoly Models, Journal of Mathematical Economics, vol. 5, 1978, pp. 173-184.

[67] Rasmanathan, R., Introduction to the Theory of Economic Growth, Springer Verlag, Berlin, 1982.

[68] Rasmussen, S., E. Mosekilde and J.D. Sterman, Bifurcations and Chaotic Behavior in a Simple Model of the Economic Long Wave, System Dynamics Review, vol. 1, 1985, pp. 92-110, Rosenberg, 
N. (1976) Perspective on Technology, Cambridge University Press, Cambridge, 1976.

[69] Ricci, G., A Differential Game of Capitalism, Optimal Control Theory and Economic Analysis (G. Feichtinger, ed.), Elsevier, Amsterdam, 1985, pp. 633-643.

[70] Schuster, H.G., Deterministic Chaos, Physik Verlag, Weinheim, FRG, 1984.

[71] Sonis, M., A Unified Theory of Innovation Diffusion, Dynamic Choice of Alternatives, Ecological Dynamics and Urban/Regional Growth and Decline, Richerche Economiche, vol. XL, 4, 1986, pp. 696-723.

[72] Sonis, M., Discrete Time Choice Models Arising from Innovation Diffusion Dynamics, Sistemi Urbani, no. 1, 1987, pp. 93-107.

[73] Sterman, J.D., A Behavioural Model of the Economic Long Wave, Journal of Economic Behaviour and Organization, vol. 5, 1985, pp. 17-53.

[74] Stewart, I., Does God Play Dice?, Basil Blackwell, Oxford, 1989.

[75] Stoneman, P., The Economic Analysis of Technological Change, Oxford University Press, Oxford, 1983.

[76] Stutzer, M., Chaotic Dynamics and Bifurcation in a Macro-model, Journal of Economic Dynamics and Control, vol. 2, 1980, pp. 253-276.

[77] Turner, J., Non-equilibrium Thermodynamics, Dissipative Structures and Self-Organization, Dissipative Structures and Spatio-temporal Organization Studies in Biomedical Research (G. Scott and J. MacMillan, eds.), Iowa State University Press, Iowa, 1980, ppp. 13-52.

[78] White, R., Transition to Chaos with Increasing System Complexity: The Case of Regional Industrial Systems, Environment and Planning A, vol. 17, 1985, pp. 387-396.

[79] Wilson, A.G., Catastrophe Theory and Bifurcation, Croom Helm, London.

[80] Yorke, J.A. and E.D. Yorke, Chaotic Behaviour and Fluid Dynamics., Hydrodynamic Instabilities and the Transition to Turbulence (H.L. Swinney and J.P. Collub, eds.), Springer-Verlag, New York, 1981, pp. 112-128. 